\title{
Substance Misuse, Firearm Violence Act and Public Policy in Nigeria
}

\author{
Gloria O. Oyagha \\ College of International Studies, Xiamen University of Technology, Xiamen, Fujian 361024, P.R. China
}

\begin{abstract}
Substance misuse and firearm violence is becoming a significant public health concern in Nigeria. This article reviews the trend of substance (drugs and alcohol) misuse in relation to firearm violence perpetration, and the policy implications associated with these findings. Publicly available data are essentially used for the narration and results from the study reveal that substance misuse are important correlates of firearm violence and various homicidal and suicide acts in Nigeria. Furthermore, the paper show that enforceable policies restricting access to firearms by persons who are intoxicated or have a history of alcohol misuse including prior convictions for alcohol-related offenses are not stipulated in the law. However, applicants with addiction history may be denied firearm access. Facts from this study suggest that restricting access to firearms for persons with a familiar record of substance misuse would be an effective consideration for violence prevention. Unambiguous definitions of substance misuse, promotion of aversion therapy or increased sensitization that will assist in behavioral modification should be encouraged.
\end{abstract}

Keywords: Alcohol, Crime, Firearm, Homicide, Substance misuse, Violence

\section{Introduction}

The World Health Organization (WHO) and the United Nations Office on Drugs and Crimes (UNODC) in its global status report on violence prevention reveal that the number of homicides in Nigeria in 2013 had reached a staggering figure of 1,897 homicides cases perpetrated (UNODC, 2014). In another report, the number of civilians in possession of handguns was estimated at 1,000,000(one million), with private gun ownership rate (both licit and illicit) of 1.5 firearms per 100 people (Dowdney, 2006, Karp, 2007). Drugs, alcohol and substance abuse have become an ever-increasing problem in Nigeria with serious health and social implications. Drug and alcohol abuse contribute significantly to the incidence of domestic aggression, violent crimes, broken homes and juvenile delinquency (Baniyi, 2008).

This narrative review summarizes existing research on relationships between substance misuse, access to and use of firearms and the perpetration of firearm violence. Findings from the literature are substituted with new tabulation of publicly-available data. This work describes the limited existing rules that restricts firearm access for reasons ranging from substance misuse, and assesses the effectiveness of restrictions for members of other high-risk groups. It also examines whether given the evidence, firearm access should be more restricted for persons with a documented history of substance misuse. "Substance misuse" is used here to refer collectively to excessive use, abuse and dependence which have distinct (and variable) definitions. Where more specific terms are used, they appear in the article under discussion. "Violence" here refers to an intentional infliction of injury on oneself or another. There are limitations to the scope of this review, oppression from inter-personal violence was not discussed, which is also associated with substance misuse (Cherpitel and Ye, 2010, Darke, 2010). Studies on firearm access and risk in relation to violence perpetration were considered, especially when it involves substance misuse. This study narrowed its focus on
Nigeria and its related cases of substance misuse, firearm access and violence perpetration and the existing policy for regulating and minimizing the possession of arms and harmful substances.

\section{Firearms, Substance Misuse and Violence}

\section{Firearms}

In Nigeria exposure to firearms is not so common compared to some parts of the world. An estimated total of one million handguns are in civilian possession, and the total number of guns (both licit and illicit) held by civilians from records in 2007 was estimated at 2,000,000 (Two million). Illegally held firearms cannot be counted in Nigeria, however in a recent report, the amount was estimated to be 0.71 illicit firearms per 100 people (USCB, 2014). In a comparison of the number of privately owned firearms in 178 countries, Nigeria ranked 34, and when comparing the rate of private firearm ownership in 178 countries, Nigeria ranked 133 (Dowdney, 2006, Karp, 2007). Moreover, firearm violence has long ranked among the leading causes of death in Nigeria, with 20\% homicidal cases in 2012 and an approximate 33,817 deaths (UNODC, 2014).

According to (ACLED, 2016), the number of arms related deaths in 2014 was 11,360, and in 2015 the number reduced to 10,677 . From the autopsies performed in the year 2010 in Rivers state, Nigeria, a total of 692 deaths related to firearms was recorded from 54 mortuary service centers operating in the state (Table 1). Homicides were the commonest manner of death with $50.5 \%$, and $69 \%$ of the weapon engaged during homicide were firearms. Other means of homicidal deaths are shown in Table 1. The average ratio of male to female homicidal deaths was pegged at a value of 124: 1 , but a wide variation was observed in gender ratios associated with weapons of homicides resulting from gunshotprecipitated deaths showing the highest ratio of 24.6:1 (Table 1) 


\section{International Journal of Science and Research (IJSR) \\ ISSN (Online): 2319-7064}

Index Copernicus Value (2013): 6.14 | Impact Factor (2014): 5.611

Table 1: Homicide record in River State Nigeria*

\begin{tabular}{|l|c|c|c|c|c|c|c|}
\hline & Homicide & Firearm & Stab & Machete/Cutlass & Strangulation & Beating & Decapitation \\
\hline Male & 929 & 665 & 88 & 84 & 6 & 86 & - \\
\hline Female & 75 & 27 & 4 & 10 & 5 & 28 & 1 \\
\hline Total & 1004 & 692 & 92 & 94 & 11 & 114 & 1 \\
\hline
\end{tabular}

*data obtained in year 2010 from autopsies carried out, adapted after Obiorah and Amakiri (2013), - data unavailable

\begin{abstract}
Alcohol and drugs
Substance use and misuse are very common in Nigeria. In 2014, the risky behavior associated with the use of drug and alcohol by Nigerian youth was reported as serious public health issue by Nkereuwem and Aakpege (2014). Heavy episodic drinking in contrast to regular moderate drinking is common among users of alcohol in Nigeria, including other parts of sub-Saharan Africa (Gureje et al., 2007). Such pattern of drinking is directly linked with intoxication, accidents, and violence (Parry, 2005). This record of alcohol-related issues accounts for many societal challenges resulting from drinking in Africa and much of the developing world (Room et al., 2002). Further, the study reveals that the frequency of occurrence of these alcoholrelated problems is as a result of binge drinking, as assessed by the American Psychiatric Association's Diagnostic and Statistical Manual abuse features (APA, 1994). Symptoms such as withdrawal and tolerance to the effects of alcohol use were reported by only $1 \%$; whereas about $4 \%$ of life time users experienced a failure to fulfill role obligations due to recurring alcohol use. In a large study of a representative sample of Nigerian adults, lifetime proportions of drug use was found as follows: alcohol 58\%, tobacco $17 \%$, sedatives $14 \%$, stimulants $2.4 \%$, and $3 \%$, cannabis (Gureje et al., 2007). The use of these illicit substances created an under-recognized problematic area for the larger public due to the harm it inflicts on users and its resultant societal burden.
\end{abstract}

\section{Substance Misuse in Relation to Firearm Violence}

Most crimes perpetrated within Nigeria are mostly carried out with the use of firearms. In previous studies, researchers have try to answer the question of allowing people with alcohol and substance misuse disorders, suicidal inclinations and other social vices to have more access to firearms. Most of these studies found some correlation between the combined presence of these factors and increased risk for interpersonal violence and self harm (Miller et al., 2009, Sorenson and Vittes, 2008, Swanson et al., 2015). Relationship between substance misuse and violence are generally observed including homicide and suicide, which are often accomplished with the aid of firearms. In 2007, a study carried out by some medical students in a Nigerian university show that the most currently used substances were mild stimulants (33\%), alcohol (13.6\%), sedatives (7.3\%) and tobacco (3.2\%) (Makanjuola et al., 2007). They found that the use of alcohol and other illicit substance (e.g. drugs) has implications on the health status of students in schools, which are strongly related to social and health problems such as increase in crime rate (often carried out with the use of firearm) and high proportion of accidental injury.

Drugs related crimes have been categorized into three distinct sections to include, Substance Use-Related Crime (these are crimes that result from or involve individuals who ingest drugs, and who commit crimes due to the effect the drug has on their thought processes and behavior); Economic-Related Crime (which are crimes where an individual commits a crime in order to fund a drug habit e.g. theft and prostitution); and System-Related Crime (crimes that result from the structure of the drug system. They include production, manufacture, transportation, and sale of drugs, as well as violence related to the production or sale of drugs, such as a turf war). From a related research in the US, individuals with drug use dependency are said to be more likely arrested for acquisitive crimes such as burglary or shop theft, or for robbery and handling stolen goods crimes often related to "feeding the habit" (NCADD, 2015). For example, in 2004, $17 \%$ of state prisoners and $18 \%$ of federal inmates reiterated that they were charged for offences related to drugs-associated money theft (BJS, 2004). The annual value of small arms and ammunition import to Nigeria is reported by the Federal Customs Office to be US\$12,912 in 2011. Firearm violence and substance misuse are very costly. Currently, the number of both legal/illegal firearm owners who are also involved in substance misuse cannot be estimated due to lack of statistical data, consequently showing the need for future research into this area.

In line with many previous studies in Nigeria and elsewhere in Africa (Abiodun et al., 1994, Flisher et al., 2003), it has been discovered that users of drugs commonly start in adolescence and young adulthood. About half of lifetime users had commenced use by the age of 20 years for alcohol, cannabis, and tobacco, and 25 years for non-prescription use of sedatives and stimulants. Even though the population prevalence of features of dependence on alcohol was higher than that of other drugs, there was no difference among users of these drugs. Clearly, while at a community level, problems related to alcohol may be higher, problems occur similarly for users of other drugs. Carrying firearms in public has been linked to both alcohol misuse and criminal activity. According to Smith (2001) in America, nationwide survey by the National Opinion Research Center found that persons reported carrying firearms in public were more likely than others to "sometimes drink more than they should" (26.1\% and $17.7 \%$, respectively) and to be arrested for a non-traffic offense ( $29.1 \%$ and $20.7 \%$, respectively). In an analysis conducted by Gureje et al. (2007), estimates of lifetime and past year psychoactive substance use (which are most associated with indiscriminate firearm perpetration) revealed that alcohol was the most commonly used drug, both in terms of lifetime history and recent use (57.6\%and $19.9 \%$, respectively).

Many studies have particularly focused on alcohol misuse and violent or forceful firearm behaviors. For example, in the nationally-representative National Comorbidity Study Replication (NCS-R) conducted in Canada, persons who 


\section{International Journal of Science and Research (IJSR) \\ ISSN (Online): 2319-7064 \\ Index Copernicus Value (2013): 6.14 | Impact Factor (2014): 5.611}

reported threatening others with a firearm were more likely than others to meet the standard criteria for alcohol abuse odds ratio (OR) of 3.21, 95\% and confidence interval (CI) of 2.31-4.45 (Casiano et al., 2008). Likewise, Swanson et al. (2015) explained that persons with alcohol or illicit drug dependence were likely to be involved in angry behaviors while carrying firearm. They further described an OR 3.5 for angry behavior and firearm carrying; OR 2.7 for angry behavior and having a firearm at home, with significance $<0.05$ in all cases. Moreover, in the light of the ground observation made during episodes of crisis situation in Nigeria, intoxicated subjects were found to brandish gun at an opponent or flees the scene of conflict, acquires firearms, and returned. Therefore, the author scrupulously suggests that intoxication may increase the likelihood of using a firearm in a conflict situation, which in turn increases the likelihood that the conflict will have a fatal outcome

\section{Suicide and Homicide}

Poor socio-cultural environment as seen in many broken homes or, parental aggressiveness may lead to hostile and violent behaviors. When this violence is directed towards self it results in suicide, and when directed towards others it results in homicide (Colson, 1973, Gold, 1965). Suicide rates are said to be very low in Africa due to less cases of depressive conditions as well as increased frequency of communal clashes that divert the aggression in the direction of others (Asuni, 1962). Depression is however not uncommon among Africans. It is presents with somatization rather than feeling of guilt and self-reproach, which is the commonest mode of presentation found among patients outside Africa (Morakinyo, 1985). In the 1990s, majority of homicides committed in Africa are said to be unpremeditated usually following family squabbles or occurring accidentally, such as during hunting expedition (Nwosu and Odesanmi, 1998). More recently, this trend have been found to be a more direct assault through the use of firearms and other malicious weapons perpetrated in the majority by a terrorist group named Boko-haram (Mark, 2015). However, compared with the United States and Serbia which have a respective homicide record amount of 88.8 and 58.2 in year 2014 for firearms per 100 residents, Nigeria's homicidal rate can be said to be less rampant at an amount of 1.5 firearms per 100 residents (NCS, 2014).

In a recent research carried out in Benin, and River states Nigeria, records of coroner autopsies between January 1998 and December 2002, and January 2000 and December 2010 respectively, at different mortuaries located across the states were undertaken (Akhiwu and Igbe, 2011, Obiorah and Amakiri, 2013). Findings from these studies suggest that, in Benin City, of the 726 medico-legal autopsies studied conducted, 138 (19\%) cases were correlated to homicide and $13(1.8 \%)$ cases were suicide related. Male to female victims ratio of 4.3 to 1 was recorded for homicide cases while it was 3.3 to 1 for suicide cases. In Rivers state, out of the 1987 autopsies performed, 1004 (50.5\%) cases were those of homicide and 15(0.8\%) cases were correlated with suicide. The ratio of male to female homicide victims in this state was 12.4:1, while 6.5:1 were recorded for suicide cases. The ages of the majority of the victims of both homicide and suicide in Benin city were between 20 and 40 years with
$50.7 \%$ of the homicides and $61.5 \%$ of the suicides falling within this age group. $69.2 \%$ of the victims were 30 years and above. Of the homicide victims, $44.7 \%$ of the males and $43.5 \%$ of the females fell into this age group. In the case of suicide victims $70 \%$ of the male victims were in this group while only one out of the 3 victims was in this age bracket. In Rivers state, the majority of the victims of both homicide and suicide were also between the ages of 20 and 40 years with $69.4 \%$ of the homicides and $53 \%$ of the suicides falling within this age group. The commonest mode of suicide was by ingestion of toxic substances (46.2\%) followed by hanging (30.8\%) and gunshot (7.7\%). For homicides in Benin city, the weapon mostly used were firearms taking about $42 \%$, while in Rivers state it was $68.9 \%$.

\section{Federal and state policies on firearms, alcohol and drugs}

The public policies relating to firearms are meant to reduce the rate of violence associated with firearm in Nigeria. In recent trend, the terrorist attacks in the northern part of Nigeria by Boko Haram have resulted in increased firearm violence. There are daily cases of suicide and homicide bombing leading to many deaths, especially in the northeastern part of the country, Maiduguri to be precise (Abubakar et al., 2015). The regulation of firearm at the federal level in Nigeria is categorized as permissive (Newton and Franklin, 1969), and the guiding gun control legislation includes the Firearms Act (Nigeria, 1990b), and the Firearms Regulations (Nigeria, 1990c). Firearms in the country are regulated by the President (Nigeria, 1990h), while the right to private gun ownership is not guaranteed by law (Nigeria, 1990e, Sherman and Tom, 2014). The state policy on firearm is to destroy surplus, collected and seized firearms rather than return them to the secondary arms market (Nigeria, 2005). To further strengthen government control on firearm, customs regulations were formulated, which necessitates the certification of intended end user of any small arms or ammunition transfer, and/or a written declaration of its intended end use (Nigeria, 2008).

Under the law, civilians are not allowed to possess machineguns, military rifles and handguns (Butchart et al., 2014, Nigeria, 1990e, g), and private possession of pistols, revolvers, fully automatic and semi-automatic assault weapons is prohibited (Nigeria, 1990f, g). However, only licensed gun owners may lawfully acquire, possess or transfer a firearm or ammunition though, applicants for a gun owner's license in Nigeria are not required to establish a genuine reason to possess a firearm (Butchart et al., 2014, Nigeria, 1990b, c, e). The minimum age for gun ownership in Nigeria is 17years (Nigeria, 1990e). Applicants wishing to acquire firearm license in Nigeria must pass a background check which considers criminal, mental and addiction record (Butchart et al., 2014, Nigeria, 1990e) however, third party character references for each gun license applicant are not required (Nigeria, 1990b, c). Where a past history, or apprehended likelihood of family violence exists, the law in Nigeria does not stipulate that a gun license should be denied or revoked (Nigeria, 1990b, c). An understanding of firearm safety and the law, tested in a theoretical and/or practical training course is not required for a firearm license however, gun owners must re-apply and re-qualify for their

\section{Volume 5 Issue 3, March 2016}




\section{International Journal of Science and Research (IJSR) \\ ISSN (Online): 2319-7064 \\ Index Copernicus Value (2013): 6.14 | Impact Factor (2014): 5.611}

firearm license every one year (Nigeria, 1990c, d). Moreover, authorities maintain a record of individual civilians licensed to acquire, possess, sell or transfer a firearm or ammunition and are permitted to possess only that which is prescribed in their license or permit (Nigeria, 1990d, e).

In Nigeria, carrying a firearm in plain view in a public place is allowed, subject to a valid permit but carrying a concealed firearm in a public place is prohibited (Butchart et al., 2014, Nigeria, 1990b, g). Maximum penalty for unlawful possession of a firearm is five years imprisonment (GunPolicy.org, 2015, Nigeria, 1990a). Authorities in Nigeria are known to have implemented voluntary firearm surrender schemes, and/or weapon seizure programs in order to reduce the number of illicit firearms in circulation (Karp, 2007, Nigeria, 2005). Federal firearm rulings are essentially silent on alcohol. Restriction of access to firearms by persons who are intoxicated or have a history of alcohol misuse including prior convictions for alcohol-related offenses are not stipulated in the law. However, applicants with addiction history may be denied firearm access (Butchart et al., 2014). Prior to the emergence of drug legislations in Nigeria, the country had been party and signatory to International Convention on Drug Prohibition. One of such convention is the Single Convention on narcotic Drugs in 1961. The International Narcotic Board was formed solely for enforcement of drug prohibition laws (Obot, 1992). It was this convention that gave impetus for Nigeria to come out with the legislation on drug prohibition entitled, National drug prohibition policies and laws in 1966 (Obot, 2004a).

In recent decade, Nigerian and UN officials' have claimed that West Africa is becoming the new centre of drug trade which have helped to conceive a specific crime problem that has served some political interests (Klantschnig, 2015). Furthermore, the analysis of the political economy of Nigerian drug policy shares affinity with the notion of policy-making as a complex adaptive system (Ratliff et al., 2015). Nigeria's policy-making in relation to drug control is considered as a resource through which State power relations are protected, at the same time disabling opportunities for drug policy reform (Rhodes and Abdool, 2016). A constraining fact is that many developing countries are faced with the reality of poverty, drug policy is often limited to law enforcement, prevention is sporadic and left to the goodwill of individuals and non-profit groups (Obot, 2004b) resources are limited, and drugs and alcohol problems compete with what policymakers might regard as more immediate problems of survival (Obot, 2007).

\section{Effectiveness of Regulation}

Despite negative sanctions on substances or drugs, there are still cases of non-conformity to the drug prohibition laws (Omadjohwoefe, 2010). Some persons in Nigeria still smuggle drugs that are prohibited into the country. India Hemp is still widely cultivated and consumed by many, including those who are so suppose to enforce such laws without any sense of control. In some instances, some of these law enforcement agents are either consumers, involved in India hemp trade or aid other dealers by accompanying them from the production sites to where they are marketed. This is a tactics used by these dealers to avoid possible check by adherent law enforcement agents (Omadjohwoefe, 2010). Furthermore, the annual budget for tobacco control in Nigeria reached USD 43,717 in year 2010 (WHO, 2010). Similarly a number of health warnings with Quandl code value of 2 and 3 were approved the same year by the law on cigarette and smokeless tobacco packaging respectively.

In conjunction with substance misuse in Nigeria, is the regulation regarding firearms. In its effort in the past, the country has destroyed 1,902 weapons in 2002/2003 (Nigeria, 2005) and 1,466 in 2004 (Karp, 2007) following its amnesty, collection and seizure program. In a related goal, Nigeria in its state policy declares the destruction of surplus, collected and seized firearms rather than return them to the secondary arms market (Nigeria, 2005). Likewise, in a similar scenario, the American government have shown that there is a good evidence that increased regulation of firearm access in the general population is effective, particularly with regard to suicide (Florentine and Crane, 2010). Florentine and Crane (2010) further showed that the most relevant research concerns and policies that selectively reduce firearm access among members of high-risk groups is the strong evidence coming from a quasi-experimental evaluation of California's decision in 1990 to extend its prohibitions to persons convicted of violent misdemeanors, for 10 years following their convictions (Wintemute, 2015).

Gruenewald et al. (1992), observed that the enforcement of existing policies on substance use (such as alcohol) and the formulation of new alcohol laws and regulations in line with new research findings would reduce alcohol consumption at individual and country level. In Nigeria, for example, the sale and consumption of alcohol are prohibited in sharia states e.g., Zamfara, Kano, Sokoto. The State Sharia laws forbid the sale and consumption of alcohol in the affected states. Further on this, in 2012, the World Health Organization (WHO) following the Quandl code sets a legal limit of 0.05 for blood alcohol concentration in Nigeria (WHO, 2012). All these are some of the effort geared towards regulating substance misuse in Nigeria. However, in other to avoid issues relating to ineffectiveness of regulation, a stiffer penalty for drug law offenders should be meted out. At the same time, agencies saddled with the responsibility of enforcing drug laws should be overhauled so as to erase the problem of complicity, and promotion of aversion therapy or covert sensitization that will assist in behavior modification should be encouraged.

\section{Responding to Available Facts}

From this review, it can be deduced that the use of alcohol, drugs and other illicit substance has implications on the health status of individuals and it is the cause of many social and health problems such as increase in crime rate (which are often carried out with the use of firearm) and high proportion of accidental injury. Conversely, it is observed that the lifetime histories of acute alcohol intoxication and substance misuse are independent risk factors for firearm violence, yet substance misuse is commonly associated with young people who are as well perpetrators of firearm violence in the society. Properly formulated policies 


\section{International Journal of Science and Research (IJSR) \\ ISSN (Online): 2319-7064 \\ Index Copernicus Value (2013): 6.14 | Impact Factor (2014): 5.611}

addressing firearm access for persons who indulge in substance misuse as highlighted in the preceding section are likely to be beneficial if adopted.

While policies seeking to reduce alcohol and other substance use-related motor vehicle deaths and injuries nationwide are widely known and published, those relating to firearm violence are still well understudied. Laws adopted elsewhere to deal with the problem (Yip et al., 2012), may prove effective to eliminate a similar defect observed in the Nigerian social system. More specifically, objective criteria for firearm access restrictions could include a specified blood alcohol concentration (BAC) limit as set by the WHO can serve as a marker of acute intoxication, and a history of multiple convictions for driving under the influence (DUI), and other alcohol or substance use-related offenses during a specified recent period of time as a marker of alcohol or substance misuse.

\section{Conclusion}

Firearm violence perpetration and substance misuse (including alcohol and drugs) are very common in Nigeria. They are interwoven in the sense that the one leads to the other. When both seem to be prevalent in a society like Nigeria, the end result is the high record of firearm violence act reported. It is worthy of note that when people who are involved in substance misuse are restricted access to firearm, the rate of violence will reduce to the barest minimum. Likewise, if policies on substance and firearm are well designed and enforced by law enforcement agents, it will go a long way to reduce the cases of violence involving firearm in Nigeria.

\section{Acknowledgement}

The author wishes to thank Mr. Olusegun Abass for his concerted effort towards the critical revision of the manuscript text and anonymous reviewers of the manuscript for their supportive comment.

\section{References}

[1] Abiodun, O. A., Adelekan, M. L., Ogunremi, O. O., Oni, G. A. \& Obayan, A. O. (1994). Pattern of Substance use among secondary school students in Ilorin, Northern Nigeria. West Afr. J. Med. 13, 91-97.

[2] Abubakar, A., Berlinger, J. \& Botelho, G. (2015). Over 50 killed in suicide blasts at northern Nigerian bus station, markets. In CNN, International Edition: https://edition.cnn.com/2015/03/07/africa/nigeriadeadly-explosions/.

[3] ACLED (2016). Armed Conflict Location \& Event Data Project. In ACLED version 6.

[4] Akhiwu, W. O. \& Igbe, A. P. (2011). Deaths with medicolegal implications in the elderly: experience from Benin City, Nigeria. Asian J Gerontol Geriatr 6, 35-37.

[5] APA (1994). Diagnostic and Statistical Manual of Mental Disorders, 4th ed. American Psychiatric Association: Washington, DC.
[6] Asuni, T. (1962). Suicide in Western Nigeria. Br Med J 2, 1091-7.

[7] Baniyi, M. (2008). Pardigms, pathologies and Practicalities- policing organized crime in England and Wales. Policing 2, 63-73. Published in National Guidance 2008.

[8] BJS (2004). Drug Use and Dependence, State and Federal Prisoners. 213530: http://www.bjs.gov/content/dcf/duc.cfmNCJ.

[9] Butchart, A., Christopher, M. \& Etienne, K. (2014). Country Profile: Nigeria. Global Status Report on Violence Prevention 2014. World Health Organisation (WHO), United Nations Office on Drugs and Crime (UNODC) and United Nations Development Programme (UNDP): Geneva.

[10] Casiano, H., Belik, S. L., Cox, B. J., Waldman, J. C. \& Sareen, J. (2008). Mental disorder and threats made by noninstitutionalized people with weapons in the national comorbidity survey replication. J Nerv Ment Dis 196, 437-45.

[11] Cherpitel, C. J. \& Ye, Y. (2010). Alcohol and Violence-Related Injuries among Emergency Room Patients in an International Perspective. J Am Psychiatr Nurses Assoc 16, 227-235.

[12] Colson, C. (1973). An objective-analytic approach to the classification of suicidal motivation. Acta Psychiatr Scand 49, 105-13.

[13] Darke, S. (2010). The toxicology of homicide offenders and victims: A review. Drug Alcohol Rev 29, 202-15.

[14] Dowdney, L. (2006). Unregistered Handgun Owners.' Neither War nor Peace: International comparisons of children and youth in organised armed violence. Rio de Janeiro: Children and Youth in Organised Armed Violence / COAV. Last accessed at http://www.gunpolicy.org/documents.

[15] Flisher, A. J., Parry, C. D. H., Evans, J., Muller, M. \& Lombard, C. (2003). Substance use by adolescents in Cape Town: prevalence and correlates. J. Adolesc. Health 32, 58-65.

[16] Florentine, J. B. \& Crane, C. (2010). Suicide prevention by limiting access to methods: a review of theory and practice. Soc Sci Med 70, 1626-32.

[17] Gold, L. H. (1965). Invitation to homicide. J Forensic Sci 10, 415-21.

[18] Gruenewald, P. J., Madden, P. \& Janes, K. (1992). Alcohol availability and the formal power and resources of state alcohol beverage control agencie. Alcoholism: Clinical and Experimental Research 16, 591-597.

[19] GunPolicy.org (2015). Penalty for Unlawful Firearm Possession. Definition and Selection Criteria. Sydney School of Public Health.

[20] Gureje, O., Degenhardt, L., Olley, B., Uwakwe, R., Udofia, O., Wakil, A., Adeyemi, O., Bohnert, K. M. \& Anthony, J. C. (2007). A descriptive epidemiology of substance use and substance use disorders in Nigeria during the early 21st century. Drug Alcohol Depend 91, 1-9.

[21]Karp, A. (2007). Completing the Count: Civilian firearms.' Small Arms Survey 2007: Guns and the City. p. 67. Cambridge University Press. Last Accesed at 25 Feb. 2016 http://www.gunpolicy.org/documents: Cambridge. 


\section{International Journal of Science and Research (IJSR) \\ ISSN (Online): 2319-7064 \\ Index Copernicus Value (2013): 6.14 | Impact Factor (2014): 5.611}

[22] Klantschnig, G. (2015). The politics of drug control in Nigeria: Exclusion, repression and obstacles to policy change. Int J Drug Policy.

[23] Makanjuola, A. B., Daramola, T. O. \& A.O., O. (2007). Psychoactive substance use among medical students in a Nigerian university. World Psychiatry 6, 112-114.

[24] Mark, M. (2015). Boko Haram's 'deadliest massacre': 2,000 feared dead in Nigeria. Last accessed at: http://www.theguardian.com/world/2015/jan/09/bokoharam-deadliest-massacre-baga-nigeria.

[25] Miller, M., Barber, C., Azrael, D., Hemenway, D. \& Molnar, B. E. (2009). Recent psychopathology, suicidal thoughts and suicide attempts in households with and without firearms: findings from the National Comorbidity Study Replication. Inj Prev 15, 183-7.

[26] Morakinyo, O. (1985). Somatic Complaint Syndromes and Depression in Nigeria. 629-634.

[27] NCADD (2015). Alcohol, Drugs and Crime National Council on Alcoholism and Drug Dependence, Inc: https://www.ncadd.org/about-addiction/alcohol-drugsand-crime.

[28] NCS (2014). All countries compared for Crime > Violent crime > Gun crime > Guns per 100 residents", Annexe I of the Small Arms Survey 2007. In Nigeria crime stat. NationMaster: Retrieved from http://www.nationmaster.com/countryinfo/stats/Crime/Violent-crime/Gun-crime/Guns-per100-residents.

[29] Newton, G. D. \& Franklin, E. Z. (1969). Firearm Licensing: Permissive vs Restrictive.' Firearms \& Violence in American Life: A staff report submitted to the National Commission on the Causes and Prevention of Violence. US Government Printing Office: Washington, DC.

[30] Nigeria (1990a). Enforcement of Act. Firearms Act, Chapter 146, Laws of the Federal Republic of Nigeria 1990. Abuja: Federal Republic of Nigeria.

[31] Nigeria (1990b). Firearms Act, Chapter 146, Laws of the Federal Republic of Nigeria 1990. Abuja: Federal Republic of Nigeria.

[32] Nigeria (1990c). Firearms Regulations, Under Section 33 , Laws of the Federal Republic of Nigeria 1990. Abuja: Federal Republic of Nigeria.

[33] Nigeria (1990d). Licensing etc. Firearms Regulations, Under Section 33 , Laws of the Federal Republic of Nigeria 1990. Abuja: Federal Republic of Nigeria.

[34] Nigeria (1990e). Licensing. Firearms Act, Chapter 146, Laws of the Federal Republic of Nigeria 1990. Abuja: Federal Republic of Nigeria.

[35] Nigeria (1990f). Personal Firearms.' Firearms Act, Chapter 146, Laws of the Federal Republic of Nigeria 1990. Abuja: Federal Republic of Nigeria.

[36] Nigeria (1990g). Prohibited Firearms. Firearms Act, Chapter 146, Laws of the Federal Republic of Nigeria 1990. Abuja: Federal Republic of Nigeria.

[37] Nigeria (1990h). Regulations and Other Powers. Firearms Act, Chapter 146, Laws of the Federal Republic of Nigeria 1990. Abuja: Federal Republic of Nigeria.

[38] Nigeria (2005). Collection and Disposal. National Report of Nigeria on its Implementation of the United Nations Programme of Action to Prevent, Combat and
Eradicate the Illicit Trade in Small Arms and Light Weapons in All Its Aspects (UNPoA). Permanent Mission of Nigeria to the United Nations: New York, NY.

[39] Nigeria (2008). National Level Implementation. National Report of Nigeria on its Implementation of the United Nations Programme of Action to Prevent, Combat and Eradicate the Illicit Trade in Small Arms and Light Weapons in All Its Aspects (UNPoA). Permanent Mission of Nigeria to the United Nations: New York, NY.

[40] Nkereuwem, E. S. \& Aakpege, Y. N. (2014). Alcohol Consumption Pattern and Risky Behaviour: A Study of University of Port Harcourt. IOSR Journal Of Humanities And Social Science (IOSR-JHSS) 19, 25-32.

[41] Nwosu, S. O. \& Odesanmi, W. O. (1998). Pattern of homicides in Nigeria--the Ile-Ife experience. West Afr $J$ Med 17, 236-8.

[42] Obiorah, C. C. \& Amakiri, C. N. (2013). Review of population based coroners autopsy findings in Rivers state of Nigeria. Forensic Sci Int 233, 1-6.

[43] Obot, I. S. (1992). Ethical and legal issues in the control of drug abuse and drug trafficking: The Nigerian case. Social Science \& Medicine 35, 481-493.

[44] Obot, I. S. (2004a). Assessing Nigeria's drug control policy, 1994-2000. International Journal of Drug Policy 15, 17-26.

[45] Obot, I. S. (2004b). Responding to Substance Use Problems in Nigeria: The Role of Civil Society Organizations. Substance Use \& Misuse 39, 1287-1299.

[46] Obot, I. S. (2007). Limits of substance-use interventions in developing countries. The Lancet 369, $1323-1325$

[47] Omadjohwoefe, O. S. (2010). Drug Prohibition and the Problem of Conformity in Nigeria. J Psychology 1 9197.

[48] Parry, C. D. (2005). South Africa: alcohol today. Addiction 100, 426-9.

[49] Ratliff, E. A., Kaduri, P., Masao, F., Mbwambo, J. K. \& McCurdy, S. A. (2015). Harm reduction as a complex adaptive system: A dynamic framework for analyzing Tanzanian policies concerning heroin use. Int J Drug Policy.

[50] Rhodes, T. \& Abdool, R. (2016). Drug harms and drug policies in Sub-Saharan Africa: Implementation science and HIV epidemics. International Journal of Drug Policy.

[51] Room, R., Jernigan, D., Carlini-Marlatt, B., Gureje, O., Makela, K., Marshall, M., Medina-Mora, M. E., Monteiro, M., Parry, C., Partanen, J., Riley, L. \& Saxena, S. (2002). Alcohol in developing societies: a public health approach. Finnish Foundation for Alcohol Studies in collaboration with the World Health Organization: Helsinki.

[52] Sherman, A. \& Tom, G. (2014). Gun Rights in National Constitutions. Marco Rubio Says Second Amendment Is Unique in Speech to NRA. Miami Herald (PolitiFact Florida): Miami, FL.

[53] Smith, T. W. (2001). National Gun Policy Survey of the National Opinion Research Center: Research Findings. National Opinion Research Center, University of Chicago: Chicago, IL. 


\section{International Journal of Science and Research (IJSR) \\ ISSN (Online): 2319-7064}

Index Copernicus Value (2013): 6.14 | Impact Factor (2014): 5.611

[54] Sorenson, S. B. \& Vittes, K. A. (2008). Mental health and firearms in community-based surveys: implications for suicide prevention. Eval Rev 32, 239-56.

[55] Swanson, J. W., Sampson, N. A., Petukhova, M. V., Zaslavsky, A. M., Appelbaum, P. S., Swartz, M. S. \& Kessler, R. C. (2015). Guns, Impulsive Angry Behavior, and Mental Disorders: Results from the National Comorbidity Survey Replication (NCS-R). Behav Sci Law 33, 199-212.

[56] UNODC (2014). Homicides in Nigeria.' Global Study on Homicide 2013: Trends, Context, Data. Vienna: United Nations Office on Drugs and Crime (UNODC),10 April.: Vienna.

[57] USCB (2014). Calculated Rates - Nigeria. Historical Population Data. In USCB International Data Base. US Census Bureau Population Division: Suitland, MD.

[58] WHO (2010). Annual budget for tobacco control in US\$ at official exchange rate - Nigeria. https://www.quandl.com/data/WHO/1089_NGA-

Annual-budget-for-tobacco-control-in-US-at-officialexchange-rate-Nigeria.

[59] WHO (2012). Legal blood alcohol concentration (BAC) limits - $\quad$ Nigeria. https://www.quandl.com/data/WHO/634_NGA-Legalblood-alcohol-concentration-BAC-limits-Nigeria.

[60] Wintemute, G. J. (2015). Alcohol misuse, firearm violence perpetration, and public policy in the United States. Prev Med 79, 15-21.

[61] Yip, P. S. F., Caine, E., Yousuf, S., Chang, S.-S., Wu, K. C.-C. \& Chen, Y.-Y. (2012). Means restriction for suicide prevention. The Lancet 379, 2393-2399. 